\title{
A 6-year Prospective Clinical Study of Laparoscopic Cholecystectomies in Kashmir Valley, India
}

\author{
Iqbal S. Mir, MS; ${ }^{1}$ Mir Mohsin, MS; ${ }^{1}$ \\ Anjum Malik, MD;2 \\ Omar Kirmani, MD; \\ Abdul Q. Shah, MS; \\ Haroon R. Zargar, MS, MRCS 5 \\ ${ }_{1}^{1 G o v e r n m e n t ~ G o u s i a ~ H o s p i t a l, ~ K h a n y a r, ~ S r i n a g a r, ~ K a s h m i r, ~ I n d i a ~}$ \\ ${ }^{2}$ Lal Ded Hospital, Srinagar, Kashmir, India \\ 3Shri Maharaja Hari Singh Hospital, Srinagar, Kashmir, India \\ ${ }^{4}$ District Hospital Baramulla, Kashmir, India \\ ${ }^{5}$ Sheri Kashmir Institute of Medical Sciences, Srinagar, Kashmir, India
}

\begin{abstract}
Objective: To evaluate the feasibility of reducing hospital stay length and the cost of laparoscopic cholecystectomies (LCs) in a developing country.

Study Design: A clinical study of patients with symptomatic cholelithiasis undergoing an LC in Gousia Hospital, District Hospital Baramulla, Modern Hospital, and Ahmed Hospital of Kashmir from January 2001 to March 2007. The main parameters evaluated were mortality, conversion, complications, re-operation, reduction in hospital stay length, and cost.

Results: One thousand, three hundred, and thirty-five patients, 1024 females and 311 males, presented for LCs. There was no mortality in the 30 postoperative days. Twenty-five cases were converted to open procedures, while one patient had common bile duct (CBD) injury. No long-term complications were noted.

Conclusion: An LC can be performed safely in small hospitals in a developing country, provided equipment is available, and the operating team members are well trained. The overall cost can be minimized by using reusable instruments, intracorporeal sutures, and self-made specimen extraction bags.
\end{abstract}

Keywords: Laparoscopic cholecystectomy, rural health, developing countries, health care costs.

Introduction

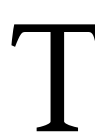
he "gold standard" for management of symptomatic cholelithiasis is a laparoscopic cholecystectomy (LC)..$^{1-3}$ Compared with an open chole-

Correspondence should be directed to

Dr. Mir Mohsin

150 Nursingarh, Balgarden, Srinagar, Kashmir, India E-mail:m_mohsin@rediffmail.com

Telephone: 009469248281 cystectomy, an LC causes less postoperative pain and postoperative pulmonary dysfunction and allows for earlier discharge from the hospital, shortened recovery periods, and improved cosmesis..$^{1,4-8}$ In the literature, large series of LCs have been reported with few complications, ${ }^{6,9-12}$ and most surgeons and patients now prefer an LC to an open cholecystectomy.

Minimal access surgery is limited in this region. Since 1995, only two teaching hospitals offer this service to a population of nearly 6 million. Due to an absence of trained laparoscopic surgeons and the 
required equipment, the benefit of laparoscopic surgery could not reach the economically deprived population, whose average daily income is $\$ 2$. A major concern that had to be overcome was the misinformation prevalent both in the local surgical fraternity and the lay population regarding the high cost of the procedure and increased LC complications.

In January 2001, laparoscopic equipment was installed in smaller hospitals catering mostly to the economically disadvantaged sections of the state of Kashmir in India. A strategy had to be developed to train the staff to perform LCs safely without the use of costly endotrainers, disposables, titanium clips. and endopouches, as the hospitals could not bear the expenses of these items.

Even though Micken performed the first operative cholangiogram in 1936, it was Mirrizi who performed the first cystic duct cholangiography in 1937, and the same procedure remains the most accepted method for performing an intraoperative cholangiography (IOC) today. ${ }^{13}$ Intraoperative cholangiography is highly sensitive in detecting common bile duct (CBD) stones, but its routine use is associated with increased costs and operating room time. The routine use of an IOC in all LC cases is still controversial. ${ }^{14}$ Conflicting reports were found in a search of literature with some authors supporting the routine use of an IOC,1,15,16 some favoring selective IOCs, 17-9 while yet others reporting no advantage of an IOC20-4 in preventing biliary tract injuries (BTIs) and missed CBD stones. An attempt was made to document in this study the results of an LC without an IOC.

This clinical study was conducted from January 2001 through the end of March 2007 with the aim of evaluating the feasibility of performing an LC in smaller health care facilities and the feasibility of decreasing the incurred cost and the length of the hospital stay without resorting to an IOC.

\section{Materials and Methods}

This study was conducted in different hospitals in Kashmir Valley from January 2001 to March 2007. Patients undergoing an LC for symptomatic cholelithiasis were the basis of this study.

Initially, only a few surgeons were trained in basic laparoscopic surgery at centers outside the state. The other team members were apprised of the video, electronic equipment, and the hand instruments. Seminars were conducted during which recorded video clips of various laparoscopic procedures also were presented to the audience. Discussions on managing complications and proper ways of maintaining the equipment were held as part of the training. An indigenously designed costless endotrainer made from an empty cardboard carton of 5\% Dextrose bottles was used to develop the hand-eye coordination of the team members, including paramedical personnel in the operating room. Safety of both the patient and the surgical equipment was emphasized.

Patients undergoing an LC were selected on the basis of history, physical examination, and radiological and laboratory evidence of gallbladder stones. Ultrasonography was focused on the characteristics of gallstones (size, number, and location), the thickness of the gallbladder wall, the status of the CBD, and assessment of the liver and pancreas.

The patients with acute cholecystitis reporting to the hospital after 72 hours of an attack, coagulopathies, and American Society of Anesthesiologists (ASA) grade III and higher were excluded. The CBD of patients with documented choledocholithiasis or those who had a history of jaundice with raised alkaline phosphatase and an ultrasound-documented CBD diameter of more then $9 \mathrm{~mm}$ were cleared by endoscopic retrograde cholangiopancreatography (ERCP) at the nearest tertiary care center prior to an LC.

Informed consent was obtained after a detailed discussion with the patient and attendants about the benefits and possible complications of an LC. To reduce the length of the hospital stay, the patients were allowed to have liquids up to 6 hours before the operation and were admitted on the day of surgery rather than before.

\section{Procedure}

General anesthesia with drugs having clearheaded recovery by endotracheal route was used in all the patients. In most of the cases a standard four port LC by the American technique was done. The Sulcus of Ruvier was used as a guide for the location of the Calot's triangle. A wide posterior window was created in the Calot's triangle, and the gallbladdercystic duct junction was identified. In patients where the Calot's triangle could not be clearly identified, a fundus-first dissection was performed. A fan retractor placed through an additional 5-mm port and 30- 
degree telescope was used to obtain a clear view of the Calot's triangle in grossly obese patients. In patients with multiple small stones in the gallbladder, the cystic duct was partially opened, and milking was done by a laparoscopic right-angled forceps to remove any cystic duct stones. Mostly 00 polyglactin sutures were placed, two on the proximal side and one on the gallbladder side on both the cystic duct and the cystic artery before cutting in between. This was done because some authors 25 report an internalization of clips into the common bile duct over a period of time and also to reduce the cost of the titanium clips. The gallbladder was usually removed through the epigastric port after reducing the stone load. In the case of infected or thickwalled gallbladders, the specimen was removed in costless endobags made from the sterile inner cover of a ryle's tube instead of costly endopouches.

Tube drains were placed selectively. To minimize the postoperative analgesic requirements, the port sites were infiltrated with a long-acting local anesthetic. Antibiotic prophylaxis in the form of two perioperative doses of intravenous third-generation cephalosporin was used. The patients were allowed oral liquids within 6-8 hours and were encouraged to have food during the evening after the operation, provided there was no nausea or vomiting.

The majority of the patients who lived in the adjoining area were discharged on the first postoperative day. Those living in outlying areas were encouraged to stay in the city for 48 hours. The patients were reviewed at one and four weeks postoperatively in the surgical outpatient department.

\section{Results}

The present study comprised 1335 patients age 7 to 81 years (mean 45.3) with symptomatic cholelithiasis who presented between January 2001 and March 2007 to different hospitals in Kashmir Valley for an LC. Table 1 tabulates the patients profile. Fifty-one patients had undergone an ERCP before an LC was conducted. The female-to-male ratio was 3.29:1. The number of patients who had undergone a previous abdominal operation, the most common being a lower segment cesarean section, was 535 . In such cases, the insertion point of the Veress needle and the first trocar site was adjusted to avoid any complications. The average operating time was 37 minutes (range: 11-190 minutes), and the mean length of
Table 1. Patients profile and other observations.

\begin{tabular}{ll}
\hline Observation & Value \\
\hline Mean age/range & 45.3 years (7-81 years) \\
Sex (female/male) & $1024 / 311$ \\
Previous abdominal surgery & 535 \\
Preoperative ERCP & 51 \\
Mean operation time & 37 minutes (11-190 min- \\
& utes) \\
Mean hospital stay (LC) & 25 hours (16-72 hours) \\
Drain & 202 \\
Analgesic use duration & 3 days (1-5 days)
\end{tabular}

postoperative hospital stay was approximately 25 hours (range: 16-72 hours).

Twenty five patients, including one re-exploration, were converted to open surgery due to various reasons tabulated in Table 2. There was no immediate mortality in our series. Table 3 tabulates the outcome of LCs in our series. Only one lateral common bile duct injury was sustained during our 6year experience, which was identified on the operating table and converted to an open laparotomy and repaired over a $\mathrm{T}$ tube. Twenty-seven patients had superficial port site infections. The most common postoperative complaint noticed was right shoulder tip pain, which usually lasted 3-5 days (Table 3). To date, we have had no complications due to spilled stones.

\section{Discussion}

Even though there was some controversy about who performed the first LC, it is now documented that it was performed in 1986 by Muhe. ${ }^{26}$ Nowadays, LCs have become the gold standard for management of cholelithiasis. ${ }^{1,6,27}$ Publications from large tertiary care centers have dealt with the surgical technique, associated complications, and the benefits of an LC. The results of this case series of LCs performed in different hospitals of a developing country are similar to those in the surgical literature from tertiary care settings and rural hospitals. , $, 4,5,8-13,28$ Both surgeons and patients now prefer LCs to open cholecystectomies, as this procedure is cost-effective, cosmetically superior, and produces far less morbidity, as documented by other studies from both large urban and small rural hospitals in developing coun- 
tries. $4,8,27,28$ Hence, access to an LC is equally important for both the urban and the rural communities of the developing world.

The problems associated with setting up a laparoscopic unit in small hospitals have to be addressed at the outset. The high setup costs, including the laparoscopic equipment and staff training, have to be considered, especially in rural hospitals with perennial financial constraints. These can be minimized by using a costless indigenously built endotrainer. The overall cost of the procedure was reduced by using reusable trocars (saving $\$ 300$ for two trocar cannula sets), intracorporeal ligatures (00 polyglactin $30-\mathrm{cm}$ length) instead of costly titanium clips (saving $\$ 10$ per clip set), and self-made endobags in place of costly endopouches (saving \$15 per pouch). In this way nearly $\$ 325$ was saved per patient, which reduced the financial burden to the hospital considerably. These means for reduction in expenditure also have been reported by other series.5,29 To prevent injuries due to blunting of the tip, the reusable trocars need to be sharpened after every 30-40 procedures.

Bleeding is one of the most frequently encountered and dangerous complications of an LC. Though bleeding is a potentially catastrophic complication, it is also the most preventable one as it is largely related to the surgical technique employed. Significant bleeding occurs in $0.5 \%$ of LCs. ${ }^{6}$ In our series, bleeding was observed in $12(0.89 \%)$ patients, but in most cases it was controlled laparoscopically. Only $6(0.44 \%)$ patients had significant bleeding that required conversion to the open procedure. In one case we had to re-explore the patient after 14 hours as there was bleeding from the posterior branch of the cystic artery, which led to hemoperitoneum.

In our series of 1335 patients, only $1(0.07 \%)$ patient sustained injury to the CBD. The incidence of this complication has been variously reported in 0 $0.8 \%$ of LCs. ${ }^{9-12,15}$ The low number of major bile duct injuries without resorting to an IOC as reported in our study is comparable to results from other centers, which recommend routine or selective IOCs. Our study thus brings into question the value of IOCs during LCs.

The reported rate of conversion to open cholecystectomy ranges between 1.88 and $10.1 \% .6,9,15,27,30,31$ In our series, 25 (1.87\%) procedures were converted to the open technique (Table 2). In most cases,
Table 2. Causes of conversion to open procedure.

Total procedures

Cause of conversion Number (percent)

Dense adhesions

perihepatic/Calot's

11

0.77

Significant

intraoperative bleeding 6

0.42

CBD injury

1

0.07

CBD stone

1

Drop in oxygen

saturation

1

0.07

Extensive

subcutaneous

emphysema

1

0.07

Dense intra-

abdominal adhesions

1

0.07

Faulty camera

0.07

Stomach carcinoma

1

0.07

Re exploration

for bleeding

1

0.07

Total

25

1.87

uncontrolled bleeding and dense perihepatic or Calot's triangle adhesions were the main reasons for conversion to the open cholecystectomy. One case of carcinoma of the stomach detected during the initial laparoscopy was converted to open procedure. It is once again emphasized that conversion to open surgery is not a failure of the surgeon but a sound decision from an experienced operator. To continue in spite of mounting difficulties is a sign of surgical immaturity.

The role of an IOC in preventing biliary tract injury (BTI) and missed CBD stones was questioned in our study. Some surgeons are of the view that an IOC is important to detect a BTI and missed CBD stones, ${ }^{1,15,16}$ while others feel that it is an unnecessary 
step. ${ }^{20-4}$ Other authors believe that an IOC should be used in indicated cases only. ${ }^{17,19}$ CBD stones occur in $3.4 \%$ of patients undergoing an LC, but more than one-third of these pass the calculi spontaneously within 6 weeks of surgery. ${ }^{31}$ It has been documented that treatment decisions based on assessment by IOC alone would result in unwarranted exploration in nearly half of the patients who had either false-positive studies or subsequently passed the calculi spontaneously. Routine IOC picks up unsuspected stones in $1-4 \%$ of cases only, needs additional radiological personnel and equipment, and increases the overall costs, especially in the setup at smaller hospitals. Hence, a routine IOC is not advisable. ${ }^{20}$ We saved about $\$ 25$ in each case by not performing an IOC without an increased incidence of complications. The other major argument against the routine use of an IOC is that a BTI has already occurred before an IOC can be performed, and hence it does not prevent a BTI.

It is advisable to thoroughly evaluate for choledocholithiasis and, if present, the patient should undergo a preoperative ERCP, followed by an immediate LC. An experienced sonologist is unlikely to miss a stone greater than 3-4 $\mathrm{mm}$ in diameter in a CBD. Small stones of this size usually migrate into the duodenum and may not require any intervention..$^{20}$ In our series we had only one case of retained CBD stones, which was managed by ERCP successfully in the postoperative period.

Cystic duct stones (CDS) should be suspected in all cases having a wide cystic duct in the presence of multiple small gallbladder calculi. Careful retraction and manipulation should therefore be done to minimize the risk of CDS slipping into the CBD. ${ }^{32}$ The partial opening of the cystic duct with milking of stones by a right-angled forceps should be employed in such cases. After missing a stone in the cystic duct early in our series it has become a policy in our unit to routinely perform this maneuver in all cases having a wide cystic duct in the presence of multiple small gallbladder calculi.

Proper case selection, especially in the early phase of the surgeon's experience, and sticking to the basic principles of an LC, such as identification of sulcus of Ranvier, making a wide posterior window, decompressing a tense gallbladder, ${ }^{33}$ proper traction of the fundus and the Hartmann's pouch, hydrodissection with warm saline, and using the fundus-first
Table 3. Morbidity during and after LC.

\begin{tabular}{|c|c|c|}
\hline Complication & Number & $\begin{array}{c}\text { Total } \\
\text { procedures } \\
\text { (percent) }\end{array}$ \\
\hline Shoulder tip pain & 227 & 17.01 \\
\hline Perforation of gallbladder & 116 & 8.69 \\
\hline Port site infections & 27 & 2.02 \\
\hline $\begin{array}{l}\text { Cystic duct stones } \\
\text { (removed) }\end{array}$ & 19 & 1.42 \\
\hline Bleeding (intra op/post op) & 13 & 0.94 \\
\hline Subcutaneous emphysema & 4 & 0.28 \\
\hline Controlled biliary leak & 4 & 0.28 \\
\hline Undetected GB malignancy & 2 & 0.14 \\
\hline $\begin{array}{l}\text { Retained CBD stones/ } \\
\text { cystic duct }\end{array}$ & 2 & 0.14 \\
\hline Stomach carcinoma & 1 & 0.07 \\
\hline Common bile duct injury & 1 & 0.07 \\
\hline Drop in oxygen saturation & 1 & 0.07 \\
\hline Cholecystohepatic duct & 1 & 0.07 \\
\hline
\end{tabular}

technique in difficult cases ${ }^{3,6}$ all can help to minimize CBD injuries, the need for IOC, and conversion to open cholecystectomy without increasing the incidence of complications.

Superficial port site infection, usually involving the port through which the specimen is removed, occurs in $0.3 \%-9.0 \%$ of all LCs. ${ }^{27,34}$ However, as we take the specimen out through the epigastric port, we had infection at that spot in $27(2.02 \%)$ of our patients. All of these were treated successfully with local wound toilet and oral antibiotics. Use of selfmade endobags to extract infected or thick-walled specimens and leaving open the skin of the port can reduce this complication.

As the patients were admitted on the day of sur- 
gery only, and ambulation and feeding were instituted early in the postoperative period, the average hospital stay was only 25 hours. Recent studies have demonstrated that a laparoscopic cholecystectomy can also be performed as day surgery.7,35 Even though this was true in most of the cases in our series, we had to keep the patients under supervision for a slightly longer period as the peripheral health care delivery system is not ideal in our state.

Successful performance of LCs requires intensive focused training, discipline, knowledge of anatomy and technology, and ongoing review of competency. We believe this series demonstrates that procedural training and ongoing practice assessment can provide timely, safe, and appropriate access to this latest surgical technique even in small hospitals of developing countries such as India to even the economically weak sections of the society. The success and complication rates in our series of 1335 attempted LCs (1310 successfully completed LCs and 25 conversions to open cholecystectomy associated with minor complications) without IOC compares favorably with results achieved in other tertiary care centers and rural hospitals.1,4,5,9,28

\section{Conclusions}

The results of this series of LCs conducted in different hospitals of a developing country are similar to those of other reports of LCs from tertiary care centers. A laparoscopic cholecystectomy can be performed safely even in small health centers of a developing country provided the required laparoscopic equipment is available. All the team members should be well trained in the procedure for which an indigenously built costless endotrainer can be used as it is not wise to "learn" on the patient. The overall cost of this operation can be reduced by $\$ 350$, especially in rural sectors of developing countries such as India, by using intracorporeal knotting in place of costly titanium clips, costless self-made endobags in place of endopouches, and properly sterilized and frequently sharpened metallic trocars without increasing the incidence of complications as substantiated by the results of our series. An intraoperative cholangiography increases the cost and the time of surgery without influencing the outcome in a substantial way. Although $\$ 350$ seems to be a small amount, it is really significant relative to the income in developing countries.
The early discharge from the hospital and early return to work strongly helps those patients who are breadwinners for the family. The authors strongly suggest that an LC should be the surgical treatment of choice for patients with cholelithiasis, even in underdeveloped countries.

\section{References}

1. Tan JT, Suyapto DR, Neo EL, et al. Prospective audit of laparoscopic cholecystectomy experience at a secondary referral centre in South Australia. ANZ J Surg. 2006;76:335-8.

2. Zehetner J, Shamiyeh A, Wayand W. Lost gallstones in laparoscopic cholecystectomy: all possible complications. Am J Surg. 2007;193:73-8.

3. Gupta A, Agarwal PN, Kant R, et al Evaluation of fundus-first laparoscopic cholecystectomy. JSLS. 2004;8:255-8.

4. Mrozowicz A, Polkowski W. Initial three years' experience with laparoscopic cholecystectomy in a district hospital: evaluation of early results and operative measures. Ann Univ Mariae Curie Sklodowska [Med]. 2004;59:26-31.

5. Champault A, Vons C, Dagher I, et al. Low-cost laparoscopic cholecystectomy. $\mathrm{Br} \mathrm{J}$ Surg. 2002;89:1602-7.

6. Vagenas K, Karamanakos SN, Spyropoulos C, et al. Laparoscopic cholecystectomy: A report from a single center. World J Gastroenterol. 2006;12:388790.

7. Berrevoet E, Biglari M, Sinove $\mathrm{Y}$, et al. Outpatient laparoscopic cholecystectomy in Belgium: what are we waiting for? Acta Chir Belg. 2006;106:537-40.

8. Patel SC, Bhatt JR. Laparoscopic cholecystectomy at the Aga Khan Hospital, Nairobi. East Afr Med J. 2000;77:194-8.

9. Morlang $\mathrm{T}$, Umscheid $\mathrm{T}$, Shelter WJ. [Laparoscopic cholecystectomy: a prospective study of 1,755 unselected patients]. [in German] Zentralbl Chir. 1995;120:353-9.

10. Schlumpf R, Klotz HP, Wehrli H, et al. A nation's experience in laparoscopic cholecystectomy. Prospective multicenter analysis of 3722 cases. Surg Endosc. 1994;8:35-41.

11. Taylor OM, Sedman PC, Jones BM, et al. Laparoscopic cholecystectomy without operative cholangiogram: 2038 cases over 5-year period in two district general hospitals. Ann R Coll Surg Engl. 1997;79:376-80. 
12. Wherry DC, Marohn MR, Malanoski MP, et al. An external audit of laparoscopic cholecystectomy in the steady state performed in medical treatment facilities of the Department of Defense. Ann Surg. 1996;224:145-54.

13. Mirrizi PL. [Operative cholangiography]. Rev Esp Enferm Apar Dig Nutr. 1950;9:306-8.

14. Piacentini F, Perri S, Pietrangeli F, et al. [Intraoperative cholangiography during laparoscopic cholecystectomy: selective or routine?] [in Italian] G Chir. 2003;24:123-8.

15. Caratozzolo E, Massani M, Recordare A, et al. Usefulness of both operative cholangiography and conversion to decrease major bile duct injuries during laparoscopic cholecystectomy. J Hepatobiliary Pancreat Surg. 2004;11(3):171-5.[PMID: 15235889]

16. Hamouda AH, Goh W, Mahmud S, et al. Intraoperative cholangiography facilitates simple transcystic clearance of ductal stones in units without expertise for laparoscopic bile duct surgery. Surg Endosc. 2007;21:955-9.

17. Sarli L, Costi R, Roncoroni L. Intraoperative cholangiography and bile duct injury. Surg Endosc. 2006;20:176-7.

18. Villeta Plaza R, Landa Garcia JI, Rodriguez Cuellar $\mathrm{E}$, et al. [National project for the clinical management of healthcare processes. The surgical treatment of cholelithiasis. Development of a clinical pathway]. [in Spanish]. Cir Esp. 2006;80:307-25.

19. Mah D, Wales P, Njere I, et al. Management of suspected common bile duct stones in children: role of selective intraoperative cholangiogram and endoscopic retrograde cholangiopancreatography. J Pediatr Surg. 2004;39:808-12.

20. Palanivelu C. Intraoperative cholangiography. In: Art of laparoscopic surgery. Textbook and atlas. New Delhi: Jaypee Brothers Medical Publishers (P) Ltd; 2007. p. 585-92.

21. Uccheddu A, Pisanu A, Cois A, et al. Can intraoperative cholangiography be avoided during laparoscopic cholecystectomy? Chir Ital. 2005;57:571-7.

22. Lepner U, Grünthal V. Intraoperative cholangiography can be safely omitted during laparoscopic cholecystectomy: a prospective study of 413 consecutive patients. Scand J Surg. 2005;94:197-200.

23. Ledniczky $G$, Fiore $N$, Bognár $G$, et al. Evaluation of perioperative cholangiography in one thousand laparoscopic cholecystectomies. Chirurgia (Bucur). 2006;101(3):267-72.

24. Barkun JS, Fried GM, Barkun AN, et al. Cholecystectomy without operative cholangiography. Implications for common bile duct injury and retained common bile duct stones. Ann Surg. 1993;218:371-7.

25. Stewart J, Cuschieri A. Adverse consequences of cystic duct closure by clips. Min Invas Ther. 1994;3:153-7.

26. Muhe E. Die erste colecystektomie durch das lparoskop. Langenbecks Arch Klin Chir. 1986;369:804. 27. Driessen PJHA, Pradhan GN. Laparoscopic cholecystectomy in a small rural hospital; CJRM. 2000;5:703.

28. Parkar RB, Thagana NG, Baraza R, et al. Experience with laparoscopic surgery at the Aga Khan Hospital, Nairobi. East Afr Med J. 2003 Jan;80:4450.

29. Ibn Ouf AM, Al Arabi Y. Intracorporeal vicryl ligatures reduces cost in some countries. Saudi J Gastroenterol. 2002;8:14-6.

30. Hölbling N, Pilz E, Feil W, et al . [Laparoscopic cholecystectomy - a meta-analysis of 23,700 cases and status of a personal patient sample]. [in German]. Wien Klin Wochenschr. 1995;107(5):158-62.

31. Collins C, Maguire D, Ireland A, et al. A prospective study of common bile duct calculi in patients undergoing laparoscopic cholecystectomy: natural history of choledocholithiasis revisited. Ann Surg. 2004;239:28-33.

32. Mahmud S, Hamza Y, Nassar AH. The significance of cystic duct stones encountered during laparoscopic cholecystectomy. Surg Endosc. 2001;15:460-2.

33. Calik A, Topaloglu S, Topcu S, et al. Routine intraoperative aspiration of gallbladder during laparoscopic cholecystectomy. Surg Endosc. 2007;21:157881.

34. Williams LF Jr., Chapman WC, Bonau RA. et al. Comparison of laparoscopic cholecystectomy with open cholecystectomy in a single center. Am J Surg. 1993;165: 459-65.

35. Leeder PC, Matthews T, Krzeminska K, et al . Routine day-case laparoscopic cholecystectomy. Br J Surg. 2004;91:312-6. 